\title{
Anticipating the content and circumstances of skill transfer: Unrealistic expectations of driver training and graduated licensing?
}

J.A. GROEGER \& A.P. BANKS

Department of Psychology

University of Surrey, Guildford, UK

*Corresponding author: Professor John A. Groeger

Department of Psychology,

University of Surrey,

Guildford, GU2 7XH.

United Kingdom

Tel.: 01483689440

Fax.: 01483689553

E-mail: j.groeger@surrey.ac.uk 


\title{
Anticipating the Content and Circumstances of skill transfer: Unrealistic expectations of driver training and graduated licensing?
}

\begin{abstract}
There is substantial evidence that driving skills improve during driver training, but the long term safety benefit of such formal training remains unproven. Restricting the exposure of newly licensed drivers to more hazardous driving circumstances, as in Graduated Driver Licensing (GDL) regimes, demonstrably reduces crash risk, but drivers remain at risk after the restrictions are eased. GDL and most other licensing regimes advocate increased basic training and practice, but thereafter require neither advanced training nor systematic increase in exposure to risk. This assumes that basic skills acquired during formal training will transfer positively to new and more demanding traffic circumstances. This paper reviews the theoretical basis for these assumptions and offers a way of systematically identifying the extent of transfer desired. We conclude that there is little theoretical or empirical foundation for the supposition that what is learned during or after training will have a safety benefit in later driving.
\end{abstract}

Keywords:

Driving; driver training; transfer of training; skill acquisition.

\section{Introduction}

Driving is a complex skill that is acquired, but not mastered, through instruction and practice. Safe driving depends on the transfer of what is learned under these restricted conditions to a wider range of circumstances not encountered during training. In Great Britain licensing follows successful demonstration of rudimentary driving skills in a practical driving test, and for several years thereafter the novice driver is at greater risk of accident than at any other time in his or her driving career. Detailed analyses of young drivers' safety records show that accident risk reduces systematically as driving experience increases, such that the greatest reduction in crash risk occurs in the first several months, or thousands of miles, of driving (Mayhew, Simpson \& Pak, 2003; Sagberg, 1998; Groeger, 2006). The increased risk of newly licensed drivers has encouraged an increasing number of jurisdictions worldwide to adopt some form of Graduated Driver Licensing (GDL) system, in which the driver's exposure to higher risk circumstances- driving at night, with passengers, more powerful vehicles, etc. is restricted until a specified time after licensing has passed. Where introduced in a non-piecemeal fashion, and when adequately enforced, the casualty reductions which have resulted are compelling evidence of the utility of the GDL approach (see Williams 2006). Some of the jurisdictions have adopted GDL licence drivers as young as 15 years of age, but even where licensing age is closer to the European norm, the safety benefits of GDL are nevertheless impressive. Advocates of GDL stress the importance of extensively practising driving skills before licensure (Williams, 2006), but in essence the safety-benefit from GDL accrues from reducing exposure to driving situations 
associated with higher risk, until, it is presumed, drivers are more capable of dealing such circumstances safely. Because GDL improves driver safety in both mid- and late-teenage new drivers, and because the durations of restricted driving are typically short, age-related maturation is not a plausible mechanism of action for the GDL-safety benefit. Instead, newly-licensed drivers are learning to be safe by driving, doing so in situations which they are likely to be able to deal with safely.

The question this paper attempts to answer is whether what is learned through formal training and restricted exposure, can be expected to benefit the driver when he or she later encounters novel, more challenging driving circumstances. This "positive transfer" from prior learning must enable the driver to evaluate circumstances not previously experienced as a driver, perhaps perform actions or combinations of actions rarely if ever performed previously, and do so if not instantaneously, then in a matter of a few hundreds of milliseconds. As a way of addressing these issues we provide an overview of the most influential ideas on how motor and judgement skills are acquired and transferred. We do so because providing a satisfactory answer requires, we believe, a shared understanding of the accounts of skill and transfer that are soundly based in empirical research, and a realistic assessment of the extent to which these can be extrapolated into the driving domain. In doing so, we identify a range of empirical and conceptual concerns. In response to these, the framework of Barnett \& Ceci (2002) is adapted for the driving context and used to clarify the requirements for the transfer of driving skills, and the likelihood of observing this transfer. We conclude by considering the implications of this for driver training and licensing.

\section{$2 \quad$ Acquiring and transferring skill}

\subsection{Skill acquisition}

For almost forty years the view of Fitts and Posner (1967) has dominated thinking on skill acquisition. In one of the earliest cognitive psychology texts, they proposed that skilled behaviours are the result of progress through three distinct phases, which they referred to as cognitive, associative and autonomous. In the first "cognitive” phase, where the beginning performer is attempting to understand the task, performance is slow, deliberate, and errorful. By the second ("associative") stage, performance is more accurate, gross errors are eliminated and patterns or sequences of performance elements are beginning to emerge. In the final "autonomous" stage, task performance is reliable, efficient, fluent, less likely to breakdown under stress and largely impervious to distraction.

\subsubsection{Skill as the creation and combination of production-rules}

Anderson and colleagues (Anderson, 1982; Taatgen \& Lee, 2003; Taatgen, 2005) have encompassed these ideas within his ACT theory, characterising learning as the transition from reliance on "declarative knowledge" (i.e. verbalisable task knowledge gained through instruction), through "knowledge compilation", until performance relies upon "procedural knowledge", i.e. productions which embody a cognitive condition and an action that will be 
performed if that condition is met. During the first stage performance is error prone and slow since working memory load is high, largely because performance depends on the learner's ability to rehearse the declarative facts. By the second stage this "verbal mediation" is rarely required, thus performance speeds up and increases in reliability. Ironically during this second stage, demands on working memory also arise through a process called "composition." During this process successive successful productions are combined into single productions, thus speeding up and improving performance. However, for composition to occur, the eliciting conditions of productions must be represented in working memory. Therefore, while working memory demand will reduce, it will not be negligible. The "proceduralisation" of productions also occurs at the second stage, and effectively eliminates the need to represent declarative information in working memory. Composition and proceduralisation, both combine steps and result in greater hierarchical control of behaviour, such that single super-ordinate units control more simple behaviour. The third stage of learning, also relies on specific processes: generalisation (in which common elements of two or more productions are made the basis of a new production which will apply more generally), discrimination (which increases the number of conditions which must be met for the production to apply thereby minimizing over-generalisation), and strengthening (in which successfully applied productions become more likely to be applied in future). These procedures effectively tune performance, permitting fast performance with a degree of virtuosity. For example, when more than one production could fire, because several available productions match the conditions in which performance is occurring, the production which leads to action is determined by preferring the more specific and the stronger of the competing productions.

\subsubsection{Skill as the storing and retrieval of episodic traces}

Memory also dominates the third account of skill acquisition considered here, but this time not as a temporary, capacity limited "working memory", but as an enduring, capacity-free "episodic" system (i.e. a memory is formed and retained for each and every instance/experience one has). According to Logan (1988; 2002), learners with no, or limited, previous experience of a particular task cannot rely on their memory, but must instead apply strategic general rules in order to proceed (what Logan calls an "algorithm"). When that situation is next encountered, the learner will not only have the algorithm available, but also an instance of their past performance. What the learner does will depend on whether the episodic memory of past performance is remembered before the algorithm can be applied. Gradually, as experiences are amassed, episodic memories, rather than offthe-cuff attempts to achieve a goal, will dominate performance. According to Logan's instance model, instanced-based performance will suffer less from distraction than algorithm-based performance, because memory retrieval is an immediate not effortful process. This assumes that an ongoing distraction does not prevent the learner from attending to those aspects of the current situation which form parts of previously stored instances of the same task. The actual retrieval of an instance is less susceptible to distraction, because the instance with the current fastest retrieval time is what the learner will remember. 
A crucial aspect of all theories is the notion that learning continues, albeit more slowly among those with greater task experience. Each of these theories predict that performance will improve with practice, becoming more accurate, reliable, and less prone to disruption. One theory does so by assuming that the knowledge on which performance is based is different, the other because memories of past performance are more plentiful. The theories also predict that learners will benefit from on-going instruction and feedback on performance, by enhancing the declarative knowledge available to the learner or by directing the learner's attention to those aspects of the task which are important (essentially simplifying the task and in turn ensuring stored instances are more relevant to future performance). Additionally, both predict that instruction and feedback can be disruptivebecause working memory limitations are exceeded, or because the poor instruction causes the learner's attention to be miss-directed or the learner to become reliant on the instruction provided. Neither theory predicts that classroom-based education will be an effective means of learning to drive, and any effect of such education would be expected to diminish as the learner gains experience of actually performing the task (e.g. "declarative knowledge can have an impact on behaviour, but that impact is filtered through an interpretative system that is well oiled in achieving the goals of the system” Anderson, 1982, p. 380).

These different conceptualisations of skill acquisition have been very successful at describing and prediction acquisition of a wide variety of skills. However, few of the tasks psychologists have considered are as complex or multifaceted as driving (Groeger, 2000). For Anderson, acquiring a complex skill is no more than the acquisition of the simpler tasks of which the complex task is comprised (see Lee \& Anderson, 2001). We doubt whether combining component skills as varied as motor and vehicular control, situational appreciation, knowledge of norms and traffic laws, interaction with other motorists, navigation, planning etc., each of which may be acquired at different rates, is as trivial a computational problem as the production system view implies. The multifaceted nature of driving also poses difficulties for the episodic instance based account of skill acquisition, unless one assumes that the memory trace rapidly retrieved by the skilled driver includes all of the motor, perceptual and conceptual elements required to respond appropriately.

\subsection{Transfer of learning}

What is learned during driver training must be transferred successfully to a broader range of circumstances than can possibly be anticipated during formal training. The purposes for which learners drive while under instruction or practising with parents are not those which will later motivate them. Furthermore, the times of day and weather conditions when driving occurs, the extent and sources of distraction, relationships with others in the vehicle, etc. will overlap very little with the circumstances which pertained before licensing. Because of this we need to understand not only how driving skill is acquired, but also how effectively acquired skills can be used under post-licensing driving conditions. While it may seem that there is a degree of consistency in the skill acquisition literature, views with regard to the transfer of what is learned contrast sharply from "Every experience 
has in it the possibilities of generalization" (Judd, 1908, p. 38) to "Reviewers are in almost total agreement that little transfer occurs” (Detterman, 1993, p. 8).

\subsubsection{Formal Discipline vs Identical elements}

The two most enduring approaches to the notion that learning transfers have venerable historical roots. John Locke's essay "On the conduct of the understanding” (1706; Garforth, 1966), are the origins of the Doctrine of Formal Discipline which asserts that training in a particular mental faculty will benefit performance of any tasks which use this faculty (see Angell, 1908). Locke recommends mathematics "as a way to settle in the mind a habit of reasoning closely and in train; not that I think it necessary that all men should be deep mathematicians, but that having got the way of reasoning, which that study necessarily brings the mind to, they might be able to transfer it to other parts of knowledge as they shall have occasion". However, while some have interpreted this generally, seeing mind as a muscle, which when exercises results in a general benefit, Locke actually advocates mathematics as a means of encouraging the application of disciplined principles of reasoning "For in all sorts of reasoning every single argument should be managed as a mathematical demonstration; the connection and dependence of ideas should be followed till the mind is brought to the source on which it bottoms and observes the coherence all along” (Locke, op. cit.).

The contrast between the generally accepted version of Locke's view, which assumes transfer of learning will be both enduring and broad, and that of Edward Thorndike's theory of identical elements could hardly be more stark. "Improvement in any single mental function need not improve the ability in functions commonly called by the same name. It may injure it. Improvement in any single mental function rarely brings about equal improvement in any other function". What they termed the "spread of practice occurs only where identical elements are concerned in the influencing and influenced function" (Thorndike \& Woodworth, 1901, p. 249-250). Because of Thorndike's close association with the origins of behaviourism, people have tended to assume "identical elements" might be confined to simple stimulus-response connections. However, the empirical studies of transfer reported in the series of Thorndike and Woodworth papers actually describe the training of estimation (of size, length, etc), text processing (e.g. detecting letter combinations among words) and memory training. What was shown in each case is that if a subset of what is originally encountered is rehearsed in subsequent training, people were better when re-tested on the original task, to the extent that the training materials repeated elements of the original learning and test conditions.

\subsubsection{Identical elements as production rules and episodic traces}

There are numerous examples of transfer of training on complex as well as simple tasks, but I will concentrate on a detailed consideration of Singley \& Anderson (1985; 1987) studies of acquisition and transfer of text editing skills, which allows a number of very important points about transfer of training to be illustrated clearly. They first identified production rules which were sufficient to simulate performance on three different text 
editors (two line editors: ED, EDT; one screen editor: EMACS), when revising pages of text in line with hand-written annotations. Some of the 107 production rules identified were shared by all three text editors, some by two, and some were unique to a specific editor. The point to be emphasised here is that painstaking analysis of the training and transfer tasks was required in order to test the suggestion that transfer occurs - even with "identical" elements. Experienced typists with no computer editing experience were trained to use a particular editor for two days, then a second editor (or the same one) for two days, and then spent a further two days using the EMACS (i.e. screen-based) editor. That is, some participants had four days of ED training, others had four days of EDT training, and some had two days each of EDT and ED training before transferring to the EMACS editor. Two control groups were also utilised, one used the EMACS editor throughout, the group other copy typed the materials for four days before switching to the EMACS editor. To press the point home, there was extensive training, lasting some 18 hours, but for just a subset of the commands and functions for which these text editors might ultimately be used.

The results are relevant here in two respects: in terms of what they show about skill acquisition and transfer in general, and more specifically in relation to the type of transfer observed. Firstly, training on this reasonably complex task, among highly proficient typists, reveals strong effects of practice. The time taken to complete an editing operation differed across editors, requiring on average for the first day 220sec (EDT), 120sec (ED) and 80sec (EMACS). These times improved markedly by the fourth day being, respectively, about one fifth, one third and one quarter of their original levels. That is, all tasks improved considerably as a function of practice, despite their differing levels of difficulty, but they improved to different extents although the amount of practice was the same in each case. Extrapolating these findings to the driving task, we would not expect all aspects of the task should improve at the same rate, which is indeed what is found (Groeger \& Brady, 2004).

Typists who transferred on the third training day from the most difficult editor (EDT) to the easier one (ED) were substantially better than those who encountered ED on the first day (220 vs $65 \mathrm{sec}$ ). Those who learned the easier ED first and then switched to the harder EDT also benefited (118 vs $47 \mathrm{sec}$ ). Learning the harder task first improved transfer performance by a factor of about 3.5, but learning the easier task first improved transfer performance less; completing an operation reduced by a factor of about 2.5. EDT to ED transfer results in greater improvement with a further day of practice on the new task. That is, transfer between two very similar tasks, even among trained operators, resulted in asymmetrical transfer gains - less gain when people learned the easier task first. On the fifth day all groups performed the editing operations using the EMACS editor. Among those who had had two days experience of EDT and ED or four days of experience of only EDT or ED an almost identical level of improvement resulted. All were faster than those who began using EMACS on their first day of training, by a factor of less than 2. It is worth noting that this gain from the past four days of different text editing training experience was about the same as the improvement made by the EMACS-only group from one additional day of EMACS training. That is, as before, there is transfer between harder and easier tasks, even whether the original and transfer tasks have less in common, but the transfer is less than the improvement gained from task-specific training. 
With regard to the nature of the transfer observed, the authors summarise that the results "support an identical elements model of transfer based on a production system representation of cognitive skill....the relative magnitudes of transfer observed were consistent with the detailed measures of productions system overlap between the editors" (Singley \& Anderson, 1987; p 267). They go on to make clear that "our results suggest that transfer was rather local and task-specific" and that while "identical elements models were quite successful at making relative predictions, they were less able to predict the magnitude in absolute terms.” (op. cit. p. 68).

Thus, if we can identify the highly task-specific conditional rules which relate a particular element of a task to a particular action, and these rules are functionally identical, we can expect to see some benefit from extensive prior training. It is unlikely that we will ever have a detailed description of the driving task at the level of the production rules required to perform each and every component task. Moreover, the vast number of studies which fail to demonstrate transfer of training, even between what may casually seem very similar tasks, should encourage further caution. A few will serve to illustrate the point.

Logan and Klapp (1992) required participants to solve arithmetic problems of the form, assuming $\mathrm{A}=1, \mathrm{~B}=2$, etc. is $\mathrm{A}+2=\mathrm{D}$ ? They did so, practising extensively using 10 letters and the numbers 2 to 5 . Over the course of 6000 practice trials performance speeded up considerably. Initially it seemed as if people effortfully counted digit-by-digit to arrive at the answer, each additional count requiring some $486 \mathrm{msec}$ in the first session of 500 trials, reducing to just $46 \mathrm{msec}$ by the twelfth and final practice block. After this the letter set used was changed to a different group of 10 letters, but the digits to be added remained the same. Performance slowed more or less to the original levels. Similarly Fendrich, Healy and Bourne (1993) showed very limited transfer between learning to multiply single digit pairs of numbers (e.g. 7 X 4) and the time taken to calculate the reverse (i.e. 4 X 7). Both studies show that when identical operations are carried out on the same stimuli, performance of that operation improves. However a slight change to the stimuli or the operation may lose most of the benefit of the prior training, because the memories specific to the practice phase are no longer are readily usable as a means of guiding performance.

These failures to observe transfer even between very similar tasks are not confined to calculation. The literature on acquisition of perceptual-motor skills is also replete with examples (e.g. see Proteau Marteniuk \& Levesque 1992; Schmidt \& Lee 1999, pp. 31821), but few are as well documented, and none have analysed the training and transfer tasks as closely in terms of productions. In order to understand better why transfer of training is sometimes, but rarely, found, we need to consider a number of other aspects of transfer which coalesce around a "spatial" metaphor.

\subsubsection{Spatial metaphors for transfer}

Transfer observed between the two very similar line based text editing systems studied by Singley and Anderson seems intuitively more likely than between, say, reading aloud a sentence written in German and providing an English translation of it. In fact, MacKay 
(1982) reports perfect transfer in exactly that circumstance, among a group of English/German bilinguals. Participants were required to produce the same sentence twelve times, pausing for some 20 seconds between each attempt. The time taken to speak the sentence aloud reduced systematically, requiring about 2 seconds by the twelfth trial, after which they were asked to produce the same sentence but in the other language. The speed at which this transfer sentence was spoken was the same as the final alternate language version, despite the entirely different sounds and motor movements required. MacKay's account of these and other similar effects relies on the suggestion that operating the phonology and musculature also activates a semantic system which is common to the speakers' English and German languages. Thus practising the sentence in one language is equivalent at the semantic level to practising it in the other language, and perfect transfer results. Transfer between two examples of the same task, as in Singley \& Anderson's two line-based text editors, is sometimes referred to as "horizontal" transfer, successful applications of a general principle can be applied to two dissimilar circumstances is described as "vertical" transfer.

A similar type of distinction has been made by Salomon and Perkins (1989), who refer to the "high road" and "low road" to transfer. The former is the effortful, time-consuming, "mindful" search for connections between learning and transfer situations. The latter occurs where conditions in the transfer context are sufficiently similar to those in a prior context of learning to trigger well-developed reflex-like responses. Salomon and Perkins provide, as an example of the lower road, the situation of learning to 'drive a car' and then taking the concepts learned in 'to drive car' and being able as a result to drive a truck "almost automatically". This seems implausible given the differences between the gears, the different effects similar amounts of steering wheel rotation, acceleration and braking characteristics, differences in legal and normative restrictions on the movement of trucks and cars, etc. An example of the "high road" would be drawing an analogy between chess and life, and applying lessons learned from the former to the latter (presumably not try to get a second queen as soon as possible or to view mating as the ultimate goal!).

Transfer has also been suggested to depend on the extent to which the contexts and motivations for performance are similar. Reder \& Klatzky (1994) refer to this general standpoint as Situated Learning, but the terms Situated Cognition or Situated Action are also used (see also Lave, 1988 ; Lave \& Wenger, 1991). Four broad principles characterise the approach. Firstly, action and the knowledge a performer possesses are specific to the situation in which the task has previously been performed. Secondly, situated accounts of learning assume that psychological models of the performer in terms of abstract information structures and processes, are inadequate, if not inappropriate, to describe performance. Thirdly, people learn by doing rather than through exposure to abstract principles, and because "current performance will be facilitated to the degree that the context more closely matches prior experience, the most effective training is to act in an apprenticeship relation to others in the performance situation" (Reder \& Klatzky, 1994; p. 5). Of course what is learned when acting as an "apprentice" under close supervision must itself be later transferred to the novel circumstance of performing alone - a transition that must be prepared for carefully (e.g. see discussion of "fading" in Patrick, 1992, p. 82). 
Reder and Klatzky also note that "theories that emphasize situated learning do not adequately deal with the transition from apprenticeship to mastery (op. cit., p. 8). Finally, Situated Learning emphasises the social context in which learning and transfer take place, asserting that understanding the social situations and interactions are essential if performance is to be fully understood.

The early influential work of Locke and Thorndike suggested that transfer of training was uncommon, and the subsequent evidence tends to support this conclusion. The detailed accounts of relatively constrained tasks such as typing and mental arithmetic demonstrate why transfer is hard to achieve, and why it will be all the more so for complex tasks such as driving. A final conceptual problem is the different forms of transfer which have been described. It may be that these forms of transfer occur in different ways. A more systematic approach for categorising transfer is needed to establish the requirements for transfer of driving skills.

\section{A framework for anticipating and quantifying transfer of driving skills}

Barnett and Ceci's (2002) excellent overview of the training transfer literature outlines a working heuristic framework which allows these disparate spatial metaphors to be integrated with other aspects of transfer. The framework provides a very useful means of systematising the literature, allowing us to map the actual empirical evidence for successful and unsuccessful transfer. The framework can also serve as a basis for checking the plausibility of the transfer of training assumptions we in the traffic safety community frequently make, exposing the extent to which they are based on relevant or indeed any evidence at all. In describing the framework and how it might be used, I have slightly altered some of Bartlett and Ceci's terminology to ease the bridging between their general account of transfer and transfer of driving skills.

\subsection{Content of anticipated transfer}

Barnett and Ceci distinguish between the "content" of what we might hope or expect to transfer from previous learning and the "circumstances" of the situation from which and to which transfer is required. The Content of anticipated transfer primarily involves:

- the requirement placed upon Learned skills, i.e. does transfer require the use of a well practised action or procedure, the creation/use of some new representation or the application of an abstract principle or heuristic?

- the type of Performance change expected, i.e. would a change be expected in, for example speed, accuracy, or the in the type of approach adopted?

- the extent of Memory demand inherent in the anticipated transfer, in terms of whether the transfer is required to be spontaneous or deliberate (i.e. will the performer be expected to immediately implement the correct course of action 
without further mental effort, be reminded explicitly in the transfer context, or at the other extreme will the performer have to think about whether anything relevant is known, select the appropriate course of action and then execute that action?)

Table 1 extends each of these dimensions to show how the transfer content varies in generality or specificity. Following, or indeed during, driver training we will expect the novice driver to, for example, brake sharply although they have never before encountered a deer on the road [Learned skill procedure]. We may also expect the driver to treat the cardboard box which has fallen from a passing truck as they would a stationary vehicle in their path [Learned skill representation], or drive more slowly in all circumstances because they have never before driven in snow [Learned skill abstract heuristic]. The sudden braking would, we would hope, be applied almost immediately, requiring deliberate decision making, whereas the application of a general "drive more slowly" in snow would, we would hope result from a careful recollection of the advice received regarding driving in snow, general experience of walking on snowy days, and some deliberate consideration of whether it should be applied in that particular circumstance. Interestingly, when driving in heavy rain for the first time, the appropriate course of action would be to slow down, in contrast to prior experience of walking and cycling, when speeding up to complete the journey faster is likely to have become the norm. We might evaluate whether the learned skill had transferred successfully by assessing how accurately or quickly the content had been implemented, but we may have a less specific criterion, such as whether the driver drove more smoothly or safely.

Table 1 Generality and specificity of transfer content

\begin{tabular}{|l|l|l|l|}
\hline & \multicolumn{3}{|c|}{ Content of anticipated transfer } \\
\hline Learned skill & Procedure (or action) & $\begin{array}{l}\text { Alternative representation } \\
\text { task requirements }\end{array}$ & $\begin{array}{l}\text { Apply abstract } \\
\text { principle across task }\end{array}$ \\
\hline $\begin{array}{l}\text { Performance } \\
\text { change }\end{array}$ & Speed/Accuracy & Smoothness/efficiency & Safety \\
\hline $\begin{array}{l}\text { Memory } \\
\text { demands }\end{array}$ & Execute only & Recognize and implement & $\begin{array}{l}\text { Recognize, select } \\
\text { and execute }\end{array}$ \\
\hline
\end{tabular}

\subsection{Circumstances of anticipated transfer}

According to almost all theorists in the area, transfer, if it occurs at all, will depend on the degree of overlap between learning and transfer contexts. Barnett and Ceci's framework helpfully identifies several of the dimensions which must be considered. When considering the Circumstances of anticipated transfer, these dimensions include:

- Knowledge Domain, for Barnett and Ceci this ranges from whether the transfer is, for example, knowledge about a rat to a mouse, or from physics class to the home. 
For transfer of driving skills, this can be interpreted as the degree of relationship between the driving manoeuvres already practised and the transfer-manoeuvre.

- Physical context, this can be interpreted as the vehicle being driven and the external circumstances.

- Temporal Context, the time since learning and/or most recent performance of the transfer-task.

- Functional Context, refers to the purpose and constraints operating at the time of learning and transfer.

- Social Context, refers to those who may witness performance and their degree of participation within it.

- Modality, for Barnett and Ceci this refers to the way in which the transfer will be assessed, such as by examination, essay or demonstration in an educational setting. Potentially, what needs to be captured here for driving purposes may already covered by the other dimensions.

In addition to the dimensions identified by Barnett and Ceci, for the framework to be a useful means of anticipating transfer of driving skills, we need to add a dimension which encompasses the level of demand imposed upon the driver by the transfer task, their own state and preoccupations, as well as distractions and demands arising from passengers, telephones calls, etc. In Table 2 we have referred to this as State-Task Situational Demand. The Near-Far dimension reflects the similarity between the original learning context and the new situation in which transfer is anticipated.

Table 2 Proximity of trained and transfer contexts

\begin{tabular}{|l|l|l|l|l|l|}
\hline & \multicolumn{5}{|c|}{ Circumstances of anticipated transfer } \\
\hline $\begin{array}{l}\text { Knowledge } \\
\text { domain }\end{array}$ & $\begin{array}{l}\text { Same } \\
\text { manoeuvre }\end{array}$ & $\begin{array}{l}\text { Similar, but } \\
\text { easier } \\
\text { manoeuvre }\end{array}$ & $\begin{array}{l}\text { Less similar, } \\
\text { but easier } \\
\text { manoeuvre }\end{array}$ & $\begin{array}{l}\text { Less similar, } \\
\text { less easy } \\
\text { manoeuvre }\end{array}$ & $\begin{array}{l}\text { Different, } \\
\text { harder } \\
\text { manoeuvre }\end{array}$ \\
\hline $\begin{array}{l}\text { Physical } \\
\text { Context }\end{array}$ & $\begin{array}{l}\text { Same car, } \\
\text { same } \\
\text { location }\end{array}$ & $\begin{array}{l}\text { Different car, } \\
\text { same } \\
\text { location }\end{array}$ & $\begin{array}{l}\text { Different car, } \\
\text { similar } \\
\text { location }\end{array}$ & $\begin{array}{l}\text { Different car, } \\
\text { less similar } \\
\text { location }\end{array}$ & $\begin{array}{l}\text { Different car } \\
\text { different } \\
\text { location }\end{array}$ \\
\hline $\begin{array}{l}\text { Temporal } \\
\text { Context }\end{array}$ & Same session & Next day & Weeks later & Months later & Years later \\
\hline $\begin{array}{l}\text { Functional } \\
\text { Context }\end{array}$ & $\begin{array}{l}\text { Formal } \\
\text { lesson }\end{array}$ & $\begin{array}{l}\text { Lesson vs } \\
\text { assessment } \\
\text { drive }\end{array}$ & $\begin{array}{l}\text { Lesson vs } \\
\text { demanding } \\
\text { drive }\end{array}$ & $\begin{array}{l}\text { Lesson vs } \\
\text { leisure drive }\end{array}$ & $\begin{array}{l}\text { Lesson vs } \\
\text { driving tired } \\
\text { late at night }\end{array}$ \\
\hline $\begin{array}{l}\text { Social } \\
\text { Context }\end{array}$ & $\begin{array}{l}\text { Driver with } \\
\text { tutor }\end{array}$ & $\begin{array}{l}\text { Driver under } \\
\text { supervision }\end{array}$ & Driver alone & $\begin{array}{l}\text { Driver with } \\
\text { peer }\end{array}$ & $\begin{array}{l}\text { Driver with } \\
\text { noisy peers }\end{array}$ \\
\hline Modality & $\begin{array}{l}\text { Driving in } \\
\text { lesson }\end{array}$ & $\begin{array}{l}\text { Driving } \\
\text { lesson vs } \\
\text { driving in } \\
\text { test }\end{array}$ & $\begin{array}{l}\text { Test vs Post } \\
\text { test driving }\end{array}$ & $\begin{array}{l}\text { Post test } \\
\text { classroom vs } \\
\text { post test } \\
\text { driving }\end{array}$ & $\begin{array}{l}\text { Classroom } \\
\text { pre-driving } \\
\text { vs post test } \\
\text { driving }\end{array}$ \\
\hline
\end{tabular}




\begin{tabular}{|c|c|c|c|c|c|}
\hline $\begin{array}{l}\text { State/Task/ } \\
\text { Situation } \\
\text { Demand }\end{array}$ & $\begin{array}{l}\text { Lone driver, } \\
\text { rested, light } \\
\text { traffic, easy } \\
\text { known } \\
\text { situation }\end{array}$ & $\begin{array}{l}\text { Lone driver, } \\
\text { rested, heavy } \\
\text { traffic, easy } \\
\text { unknown } \\
\text { situation }\end{array}$ & $\begin{array}{l}\text { Lone driver, } \\
\text { tired, heavy } \\
\text { traffic, } \\
\text { unknown } \\
\text { situation }\end{array}$ & $\begin{array}{l}\text { Distracted } \\
\text { driver, new, } \\
\text { easy } \\
\text { situation }\end{array}$ & $\begin{array}{l}\text { Tired driver, } \\
\text { distracted, } \\
\text { new, difficult } \\
\text { situation }\end{array}$ \\
\hline
\end{tabular}

Barnett and Ceci, having reviewed a very substantial body of empirical literature can point to just a handful of studies which provide reliable evidence of "far" transfer on any single dimension. They find none that show the level of far transfer that we in the traffic safety community assume will result from driver training and on-going practice.

\section{$4 \quad$ Discussion and implications}

Some twenty years ago, Brown, Groeger and Biehl (1987) carried out a review of the effectiveness of driver training. The conclusion reached, that there was little or no evidence to show a safety benefit of initial formal driver training, was unpopular. Discussing this conclusion, the authors reflected upon the inherent difficulty of providing adequate empirical evidence for a safety benefit, bemoaned the absence of longitudinal studies of drivers' skill development, and indicated the lack of theoretical basis for driver training practices. Since that review much has changed.

Other researchers have reached similar conclusions about the efficacy of current driver education and training (see Mayhew et al., 1998; Christie, 2001), and the emphasis in young driver safety interventions has shifted to licensing, to considerable effect where GDL is fully implemented and enforced (Williams, 2006). Detailed analyses of driver education have been funded by the EU (e.g. GADGET - see Peräaho, Keskinen \& Hatakka 2003, TRAINER, see Nalmpantis, Naniopulos, Bekiasis, Panou, Gregersen, Falkmer, Naten \& Dols 2005), licensing age in Sweden has been altered in order to permit more practice before full licensing (see Sagberg \& Gregersen, 2005), and at least two longitudinal studies of drivers' skill acquisition have been published (e.g. Groeger \& Clegg, 2000; Groeger \& Brady, 2004). The latter provide convincing evidence of very substantial and reliable improvements in driving skill in the course of training, and that these improvements rely on both formal instruction and extensive practice. However, our own post-driving test performance data (see Groeger \& Brady, 2004), together with the accident analyses of newly licensed drivers by, among others, Mayhew et al (2003), leaves us equally convinced that conventional approaches to training are unlikely to produce a lasting safety benefit. By failing to consider whether we should expect any substantial transfer of pre-licence learning to later driving, we believe we have required too much of conventional driver training, and may be in danger of missing a further enhancement of graduated driver licensing. It is worth emphasising here that we acknowledge that slow, deliberate, effortful, and probably verbally mediated transfer of old skills to new situations can and does take place. Positive transfer of any kind is less likely whether the driver is distracted, sleepy or otherwise unable to allocate substantial attentional resources to the task at hand. What we believe our 
review has shown is that transfer to more novel circumstances which would be sufficient to enable appropriate more or less instantaneous reactions, as might be required in hazardous situations, does not take place.

Although an admittedly extreme position, the rudimentary skills newly licensed drivers have developed should not be expected to transfer to novel driving circumstances. Increased amounts and variability of safe-situation practice under supervision will benefit pre- and newly- licensed drivers, even if this does not enhance transfer to later driving. Neither should we simply expect that the post-GDL driver will be any better able to handle the extremities of demand GDL has temporarily spared them from. There are, regrettably, some very hard questions we must attempt to answer. Precisely what knowledge do we expect to be gained during the restricted driving period? How do we expect this will transfer to some unanticipated circumstance several months or even years ahead? Without satisfactory answers, underpinned with empirical evidence, our view is that we should require newly licensed drivers to participate in post-license training and require that they demonstrate their competence in more demanding circumstances, before restrictions are eased. Doing so would maximise the likelihood of "near" transfer, and reduce the likelihood of encountering those "far" circumstances where positive transfer is unlikely to reach.

\section{Acknowledgements}

We wish to thank Jo Bower, whose comments on the paper greatly increased the chances of the successful transfer of its content and Bruce Simons-Morton for the discussions which provoked its writing. The first author also wishes to thank Neville Stanton and the Institute of Advanced Motorists who organized and supported the conference at which these views were first aired.

\section{References}

ANDERSON, J.A., 1982, Acquisition of cognitive skill. Psychological Review, 89, 369406.

ANGELL, J.K., 1908, The doctrine of formal discipline in the light of the principles of general psychology. Educational Review, 36, 1-14.

BARNETT, S.M. and CECI, S.J., 2002, When and where do we apply what we learn?: A taxonomy for far transfer. Psychological Bulletin, 128, 612-637.

BROWN, I.D., GROEGER, J.A. and BIEHL, B., 1987, Is training contributing enough to road safety? In Road Users \& Traffic Safety, J.A. Rothengatter and R.A. de Bruin (Eds.), (Van Gorcum: Assen/Maastricht), pp. 135-56.

CHRISTIE R., 2001, The effectiveness of driver training as a road safety measure: a review of the literature, (Victoria, Australia: Royal Automobile Club of Victoria Ltd).

DETTERMAN, D. K., 1993, The case for the prosecution: Transfer as an epiphenomenon. In Transfer on trial: Intelligence, cognition, and instruction, D. K. Detterman and R. J. Sternberg (Eds.), (), (Norwood, NJ: Ablex), pp. 1-24. 
FENDRICH, D.W., HEALY, A.F. and BOURNE, L.E. Jr., 1993,Mental arithmetic: training and retention of multiplication skill. In Cognitive Psychology Applied, C Izawa (ed.), (Hillsdale, NJ: Erlbaum), pp. 111-33.

FITTS, P.M., and POSNER, M.I., 1967, Learning and skilled performance in human performance, (Belmont CA: Brock-Cole).

GROEGER, J.A. and BRADY, S., 2004, Differential effects of formal and informal driver training. Road Research Report No. 42, (London: HMSO).

GROEGER, J.A. and CLEGG, B.A., 2000, Practice and instruction when learning to drive. Road Research Report No. 14, (London: HMSO).

GROEGER, J.A., 2000, Understanding driving: Applying cognitive psychology to a complex everyday task. (Hove: Psychology Press).

GROEGER, J.A., 2006, Youthfulness, inexperience and sleep loss: the problems young drivers face and those they pose for us. Injury Prevention, 12(Suppl I):19-24.

JUDD, C. H., 1908, The relation of special training to general intelligence. Educational Review, 36, 28-42.

LAVE, J., 1988, Cognition and practice: Mind, mathematics, and culture in everyday life, (Cambridge: Cambridge University Press).

LAVE, J. and WENGER, E., 1991, Situated learning: Legitimate peripheral participation, (Cambridge: Cambridge University Press).

LEE, F.J. and ANDERSON, J.R., 2001, Does learning of a complex task have to be complex? A study in learning decomposition. Cognitive Psychology, 42, 267-316.

LOCKE, J., 1706, Of the Conduct of the Understanding. F. W. Garforth (Ed.), New York, 1966. Hypertext by ITL at Teachers College, Columbia University, 1995.

LOGAN, G. D., 1988, Towards an instance theory of automatization. Psychological Review, 95, 492-527.

LOGAN, G. D., 2002, An instance theory of attention and memory. Psychological Review, 109, 376-400.

LOGAN, G. D. and KLAPP, S. T., 1992, Automatizing alphabet arithmetic: I. Is extended practice necessary to produce automaticity? Journal of Experimental Psychology: Learning, Memory and Cognition, 17, 179-195.

MACKAY, D.G., 1982, The problems of flexibility, fluency, and speed-accuracy trade-off in skilled behavior. Psychological Review, 89, 483-506.

MAYHEW D.R., SIMPSON H.M. and PAK A., 2003, Changes in collision rates among novice drivers during the first months of driving. Accident Analysis and Prevention, 35, 683-91.

MAYHEW D.R., SIMPSON H.M., WILLIAMS A.F. and FERGUSON, S.A., 1998, Effectiveness and role of driver education and training in a graduated licensing system. Journal of Public Health Policy, 19, 51-67.

NALMPANTIS, D., NANIOPOULOS, A., BEKIARIS, E., PANOU, M., GREGERSEN, N.P., FALKMER, T., NATEN, G. and DOLS J.F., 2005,. "Trainer" Project: Pilot Applications for the evaluation of new driver training technologies. In Traffic and 
Transport Psychology: Theory and Application, G. Underwood (Ed.), (Elsevier: Amsterdam) pp 141-156.

PATRICK J., 1992, Training: research and practice. (London: Academic Press).

PERAAHO, M., KESKINEN, E. and HATAKKA, M., 2003, Driver competence in a hierarchical perspective; Implications for driver education. University of Turku, Traffic Research.

PROTEAU, L., MARTENIUK R.G. and LEVESQUE L., 1992, A sensorimotor basis for motor learning: evidence indicating specificity of practice. Quarterly Journal of Psychology, 44, 557-75

REDER, L. and KLATZKY, R., 1994, Transfer: Training for Performance. In Learning, Remembering, Believing: Enhancing Human Performance, D. Druckman and R.A. Bjork (Eds.), (Washington, D.C.: National Academy Press), pp. 25-56.

SAGBERG F., 1998, Month by month changes in accident risk. Paper presented at the International Association of Applied Psychology, San Fransisco, 9-14 August.

SAGBERG, F. and GREGERSEN, N.P., 2005, Effects of lowering the age limit for driver training. In Traffic and Transport Psychology: Theory and Application, G. Underwood (Ed.), (Elsevier: Amsterdam), pp. 171-180.

SALOMON, G. and PERKINS, D.N., 1989, Rocky roads to transfer: rethinking mechanisms of a neglected phenomenon. Educational Psychologist, 24, 113 - 142.

SCHMIDT, R.A. and LEE T.D., 1999, Motor Control and Learning-A Behavioral Emphasis, (Champaign, IL: Hum. Kinetics).

SINGLEY, M.A. and ANDERSON, J.A., 1985, The transfer of text-editing skill. International Journal of Man-Machine Studies, 22, 403-422.

SINGLEY, M.A. and ANDRSON, J.A., 1987, A key-stroke analysis of learning and transfer in text editing. Human Computer Interaction, 3, 223- 271.

TAATGEN, N.A, 2005, Modeling Parallelization and Flexibility Improvements in Skill Acquisition: From Dual Tasks to Complex Dynamic Skills. Cognitive Science, 29, 421455.

TAATGEN, N.A. and LEE, F.J., 2003, Production Compilation: A simple mechanism to model Complex Skill Acquisition. Human Factors, 45, 61-76.

THORNDIKE, E.L. and WOODWORTH, R.S., 1901, The influence of improvement in one mental function upon the efficiency of other functions. Psychological Review, 8, 247-261.

WILLIAMS, A.F., 2006, Young driver risk factors: successful and unsuccessful approaches for dealing with them and an agenda for the future. Injury Prevention, 12(Suppl I), 4-9. 